\title{
ERRATUM
}

\section{Erratum to: Risk of over-diagnosis of hypotension in children: a comparative analysis of over 50,000 blood pressure measurements}

Samiran Ray ${ }^{1,2^{*}} \mathbb{D}$, Libby Rogers ${ }^{3}$, David P. Noren ${ }^{4}$, Ranjana Dhar ${ }^{2}$, Simon Nadel ${ }^{5}$, Mark J. Peters ${ }^{1,2}$ and David P. Inwald ${ }^{5}$

๑ 2017 Springer-Verlag GmbH Germany and ESICM

\section{Erratum to: Intensive Care Med DOI 10.1007/s00134-017-4843-8}

This article contained two errors:

1. In the last sentence of the penultimate paragraph, the post-test odds should have been stated as 26.77 , not 21 . The remainder of the results are not affected.

2. The first sentence of the last paragraph should have read "These data demonstrate that use of low NIBP measurements in isolation to guide treatment for hypotension in children could lead to over-treatment".

The authors and the publisher, respectively, apologize for these errors and any inconvenience caused.

\section{Author details}

1 Respiratory, Critical Care and Anaesthesia Section, UCL GOS Institute of Child Health, 30 Guildford Street, London WC1N 1EH, UK. ${ }^{2}$ Paediatric Intensive Care Unit, Great Ormond Street Hospital NHS Trust, London, UK. ${ }^{3}$ UCL Clinical Operations Research Unit, University College London, London, UK. ${ }^{4}$ Philips Research North America, Cambridge, MA 02141, USA. ${ }^{5}$ Paediatric Intensive Care Unit, St Mary's Hospital, Imperial College Healthcare London NHS Trust, London, UK.

\footnotetext{
*Correspondence: samiran.ray@gosh.nhs.uk

${ }^{1}$ Respiratory, Critical Care and Anaesthesia Section, UCL GOS Institute of Child Health, 30 Guildford Street, London WC1N 1EH, UK Full author information is available at the end of the article
}

The online version of the original article can be found under doi:10.1007/s00134-017-4843-8.

\section{国 Springer}

